\title{
Identification of potential key genes and high-frequency mutant genes in prostate cancer by using RNA-Seq data
}

\author{
ZE ZHANG ${ }^{1}, \mathrm{HE} \mathrm{WU}^{2}, \mathrm{HONG} \mathrm{ZHOU}^{3}, \mathrm{YUNHE} \mathrm{GU}^{2}, \mathrm{YUFENG} \mathrm{BAI}^{1}$, \\ SHILIANG YU ${ }^{1}$, RUIHUA AN ${ }^{1}$ and JIPING $\mathrm{QI}^{2}$ \\ Departments of ${ }^{1}$ Urology Surgery, ${ }^{2}$ Pathology and ${ }^{3}$ Respiration, The First Affiliated Hospital \\ of Harbin Medical University, Harbin, Heilongjiang 150001, P.R. China
}

Received April 15, 2016; Accepted June 22, 2017

DOI: $10.3892 / 01.2018 .7846$

\begin{abstract}
The aim of the present study was to identify potential key genes and single nucleotide variations (SNVs) in prostate cancer. RNA sequencing (RNA-seq) data, GSE22260, were downloaded from the Gene Expression Omnibus database, including 4 prostate cancer samples and 4 normal tissues samples. RNA-Seq reads were processed using Tophat and differentially-expressed genes (DEGs) were identified using the Cufflinks package. Gene Ontology enrichment analysis of DEGs was performed. Subsequently, Seqpos was used to identify the potential upstream regulatory elements of DEGs. SNV was analyzed using Genome Analysis Toolkit. In addition, the frequency and risk-level of mutant genes were calculated using VarioWatch. A total of 150 upregulated and 211 downregulated DEGs were selected and 25 upregulated and 17 downregulated potential upstream regulatory elements were identified, respectively. The SNV annotations of somatic mutations revealed that $65 \%$ were base transition and $35 \%$ were base transversion. At frequencies $\geq 2$, a total of 17 mutation sites were identified. The mutation site with the highest frequency was located in the folate hydrolase 1B (FOLH1B) gene. Furthermore, 20 high-risk mutant genes with high frequency were identified using VarioWatch, including ribosomal protein S4 Y-linked 2 (RPS4Y2), polycystin 1 transient receptor potential channel interacting $(P K D I)$ and $F O L H I B$. In addition, kallikrein $1(K L K l)$ and $P K D 1$ are known tumor suppressor genes. The potential regulatory elements and high-frequency mutant genes (RPS4Y2,KLK1, PKD1 and
\end{abstract}

Correspondence to: Dr Ruihua An, Department of Urology Surgery, The First Affiliated Hospital of Harbin Medical University, 23 You Zheng Street, Harbin, Heilongjiang 150001, P.R. China E-mail: ruihuaanana@hotmail.com

Dr Jiping Qi, Department of Pathology, The First Affiliated Hospital of Harbin Medical University, 23 You Zheng Street, Harbin, Heilongjiang 150001, P.R. China

E-mail: jpqiiqiqi@126.com

Key words: differentially-expressed genes, prostate cancer, RNA sequencing, single nucleotide variation, high-frequency, high-risk
FOLH1B) may have key functions in prostate cancer. The results of the present study may provide novel information for the understanding of prostate cancer development.

\section{Introduction}

Prostate cancer is the sixth leading cause of cancer-associated mortality in males worldwide, and is the second leading cause among males in the United States (1). The morbidity rates of prostate cancer vary widely across the world and are less frequent in South and East Asia, compared with that in Europe and United States (2). In spite of the high incidence, the etiology of prostate cancer remains unknown (3). Furthermore, early prostate cancer is typically asymptomatic, with $\sim 66 \%$ of patients diagnosed with prostate cancer exhibiting no symptoms, preventing the early control of prostate cancer (4). The identification of novel therapeutic targets is required to diagnose early prostate cancer.

Established risk factors of prostate cancer include age, race and exhibiting a family history of prostate cancer (5). Genetic factors, which may increase the risk of developing prostate cancer, are associated with ethnicity and family history of the disease (6). A number of different genes have been implicated in the development of prostate cancer $(7,8)$. A previous study validated that prostate cancer is prone to recurrent gene fusions of androgen-regulated genes, including transmembrane protease serine 2 (TMPRSS2), solute carrier family 45 member 3 and $\mathrm{N}$-myc downstream regulated 1, and E26 transformation-specific (ETS) transcription factors, including ERG ETS transcription factor $(E R G)$ and ETS variant 1 (9). In addition, loss of tumor suppressor genes [including Kruppel-like factor 6 (10), BTG anti-proliferation factor 3 (11) and phosphatase and tensin homolog (12)] and activation of oncogenes [including nuclear receptor coactivator 2 (NCOA2) and MYC proto-oncogene bHLH transcription factor] in the carcinogenesis of prostate cancer have been identified (13). Although previous studies have revealed a number of candidate genes, the causes of prostate cancer remain unclear.

Next-generation RNA sequencing (RNA-seq) enables the identification of genes that may be susceptible to prostate cancer (14). On the basis of RNA-seq data, the transcriptome profiles of primary prostate cancer are identified, including gene fusions, long non-coding RNAs, alternative splicing and somatic 
mutations (9). Ren et al (15) used RNA-seq to profile genetic aberrations in Chinese patients with prostate cancer and identify three recurrent gene fusions, including TMPRSS2-ERG, ubiquitin specific peptidase 9 Y-linked-testis-specific transcripts, Y-linked 15 on chromosome Y and the interchromosomal translocation of CTAGE family member 5 ER export factor-KH RNA binding domain containing signal transduction associated 3. Kannan et al (16) investigated chimeric RNAs expressed in human prostate cancer and obtained 1.3 billion sequence reads, which enabled the identification of 2,369 chimeric RNA candidates for distinguishing of prostate cancer. On the basis of this, $\mathrm{Xu}$ et al (17) identified 116 disruptive mutations in 92 genes with high confidence, including a frameshift insertion/deletion in the coding region of the TNF superfamily member 10 gene associated with apoptosis. However, differentially-expressed genes (DEGs) between prostate cancer samples and normal control samples were not investigated, and a number of somatic mutations remain unknown.

In the present study, raw RNA-seq data from the study by Kannan et al (16) was downloaded from the National Center for Biotechnology Information database and analyzed by a number of bioinformatics methods. First, DEGs between prostate cancer samples and normal control samples were identified. Subsequently, functional enrichment analysis of DEGs was performed, to understand the underlying molecular mechanisms of prostate cancer. Furthermore, the upstream regulatory elements of DEGs were identified and analyzed. In addition, single nucleotide variations (SNVs) were determined and the somatic mutation sites were annotated. The risk level of SNVs was assessed for selection of SNVs with high risk and high frequency. These candidate genes may contribute to further the understanding of prostate cancer.

\section{Materials and methods}

Raw RNA-seq data. The RNA-seq data GSE22260 (16) were downloaded from the Gene Expression Omnibus (www.ncbi.nlm.nih.gov) database, including 4 prostate cancer samples (GSM554078, GSM554082, GSM554086 and GSM554088) and 4 matched normal tissues samples (GSM554118, GSM554120, GSM554122 and GSM554124), respectively. The Gleason score of the four cancer samples were 7, 7, 7 and 6 (18). The sequencing platform was Illumina Genome Analyzer IIx (Illumina, Inc., San Diego, CA, USA). Reads were generated via a paired-end approach.

Read alignment. All RNA-Seq reads were mapped to the reference human genome (hg19) of the University of California Santa Cruz (Santa Cruz, CA, USA) by using Tophat software (19). Only the reads that mapped to specific genome locations were retained. A maximum of two mismatches in each read were permitted. Other parameters were set up according to the default settings of Tophat.

DEG analysis. On the basis of Refseq gene annotation (20), transcripts were assembled using Cufflinks (version 0.9.3) (21). Subsequently, the gene expression levels of transcripts were calculated using Cuffdiff (part of the Cufflinks package), on the basis of the fragments/kilobase/million reads method (22). The differentially expressed transcripts were identified by
Table I. Comparison between identified DEGs from prostate cancer samples and normal control samples.

\begin{tabular}{lccl}
\hline Expression & DEGs & $\begin{array}{c}\text { TF } \\
\text { counts }\end{array}$ & \multicolumn{1}{c}{ TF genes } \\
\hline Downregulated & 211 & 4 & $\begin{array}{l}\text { IFII6, NEUROG3, } \\
\text { RARG, SIMI }\end{array}$ \\
Upregulated & 150 & 4 & $\begin{array}{l}\text { DMBX1, NCOA2, } \\
\text { ONECUT2, ZNF83 }\end{array}$
\end{tabular}

DEGs, differentially-expressed genes; TF, transcription factor.

calculating the fold change in the transcript and Student's t-tests in Cufflinks were performed to assess the difference. Transcripts with a $\log _{2}$ fold change $>2$ and $\mathrm{P}<0.05$ were considered DEGs.

Function enrichment analysis of DEGs. Gene Ontology (GO) (23) enrichment analysis was performed for the aforementioned DEGs, on the basis of the Database for Annotation, Visualization and Integrated Discovery database (www.david.niaid.nih.gov) (24). GO categories were classified into biological process (BP), molecular function and cellular component (CC) GO-terms. $\mathrm{P}<0.05$ was set as the threshold criterion.

DEGs which demonstrated regulatory function were selected, labeled and inputted into the tumor suppressor gene (25) database (bioinfo.mc.vanderbilt. edu/TSGene) and the tumor-associated gene (26) database (www.binfo.ncku.edu.tw/TAG/GeneDoc.php) to select cancer-related genes (tumor suppressor genes or oncogenes) for additional analysis.

Upstream regulatory elements of DEGs. In the present study, the upstream region $(1.5 \mathrm{~kb})$ of the transcription start site was defined as the promoter region. For the promoter region of upand downregulated DGEs, motif identification was performed using Seqpos (27) to identify transcription factors. $\mathrm{P}<0.00001$ and the frequency of motif targeted sequences $>50 \%$ of upand downregulated DEGs were set as the threshold criteria.

Identification of SNVs. The Genome Analysis Toolkit (28) software (available at www.broadinstitute.org/gatk) was used to identify the SNVs. The coverage of each credible SNV was $>5 \mathrm{x}$. The minimum quality score of reliability SNV was 30 and SNVs with a quality score $>50$ were defined as high reliability SNVs. Based on the single nucleotide polymorphism (SNP) sites documented in dbSNP137 and 1,000 genome databases, the already known SNV callings in tumor tissues were removed. To remove the interference of RNA editing in the transcriptome, SNV calling was optimized by combining with RNA-seq data of normal controls.

Somatic mutation sites annotation and high-risk mutation sites assessment. The VarioWatch (29) software (genepipe.ncgm.sinica.edu.tw/variowatch/main.do) was used to annotate the SNVs in coding sequence and assess the functional impact of gene products, on the basis of the risk 
Table II. Ten most significant GO terms of up- and downregulated DEGs in prostate cancer.

A, Upregulated DEGs

\begin{tabular}{llrl}
\hline Category & \multicolumn{1}{c}{ Term } & Count, $\mathrm{n}$ & P-value \\
\hline CC & GO:0000786; nucleosome & 5 & 0.0006 \\
BP & GO:0006333; chromatin assembly or disassembly & 6 & 0.0016 \\
CC & GO:0032993; protein-DNA complex & 5 & 0.0020 \\
BP & GO:0006334; nucleosome assembly & 5 & 0.0024 \\
BP & GO:0031497; chromatin assembly & 5 & 0.0027 \\
BP & GO:0065004; protein-DNA complex assembly & 5 & 0.0032 \\
BP & GO:0034728; nucleosome organization & 5 & 0.0034 \\
BP & GO:0051223; regulation of protein transport & 5 & 0.0070 \\
BP & GO:0006323; DNA packaging & 5 & 0.0077 \\
CC & GO:0000785; chromatin & 6 & 0.0083 \\
\hline
\end{tabular}

B, Downregulated DEGs

\begin{tabular}{|c|c|c|c|}
\hline Category & Term & Count, $\mathrm{n}$ & P-value \\
\hline $\mathrm{CC}$ & GO:0005902; microvillus & 4 & 0.0033 \\
\hline $\mathrm{CC}$ & GO:0031226; intrinsic to plasma membrane & 20 & 0.0055 \\
\hline $\mathrm{BP}$ & GO:0009100; glycoprotein metabolic process & 7 & 0.0082 \\
\hline $\mathrm{BP}$ & GO:0009101; glycoprotein biosynthetic process & 6 & 0.0120 \\
\hline $\mathrm{CC}$ & GO:0044459; plasma membrane part & 29 & 0.0129 \\
\hline $\mathrm{CC}$ & GO:0046658; anchored to plasma membrane & 3 & 0.0144 \\
\hline $\mathrm{BP}$ & GO:0006955; immune response & 13 & 0.0162 \\
\hline $\mathrm{CC}$ & GO:0005887; integral to plasma membrane & 18 & 0.0196 \\
\hline $\mathrm{CC}$ & GO:0005886; plasma membrane & 43 & 0.0196 \\
\hline $\mathrm{BP}$ & GO:0043413; biopolymer glycosylation & 5 & 0.0250 \\
\hline
\end{tabular}

DEGS, differentially-expressed genes; GO, Gene Ontology; CC, cellular component; BP, biological process.

Table III. Potential upstream regulatory elements of DEGs in prostate cancer.

\begin{tabular}{lcl}
\hline Expression & Count, $\mathrm{n}$ & \multicolumn{1}{c}{ Candidate TFs } \\
\hline Upregulated & 25 & BARHL1, CD200, CEBPA, \\
& CUX1, EN1, ESX1, HNF4A, \\
& $H O X A 5, I R F 8, L H X 6, M E O X 1$, \\
& $N O X 1, N R 1 H 4, P A X 6, P B X 1$, \\
& $P H O X 2 A, P I T X 2, P R K R A$, \\
& $R A X, R O R A, S I X 4, T C F 7 L 2$, \\
& VAX2, VSX2, ZEB1 \\
& $C D X 1, E P A S 1, F O X C 1$, \\
& $H M X 1, H M X 3, H O X A 10$, \\
& $H O X A 3, H O X C 12, H S F 1$, \\
& $H S F 2, I K Z F 2, I R F 1, I R F 2$, \\
& $M S X 1, N R 3 C 1, P O U 2 F 1$, \\
& $Z E B 1$
\end{tabular}

DEGs, differentially-expressed genes; TF, transcription factor. assessment of the software. The SNVs with high-risk level of abnormal protein function were selected.

\section{Results}

Differential expression analysis and functional enrichment analysis. According to the differential expression analysis of paired RNA-seq data between prostate cancer samples and normal control samples, a total of 150 upregulated and 211 downregulated DEGs were selected (Table I). On the basis of the annotation information of transcription factors, 8 differentially-expressed transcription factors were identified, 4 of which were upregulated [interferon- $\gamma$ inducible protein 16 (IFI16), neurogenin 3 (NEUROG3), retinoic acid receptor- $\gamma(R A R G)$ and single-minded family bHLH transcription factor 1 (SIM1)] and 4 were downregulated [diencephalon/mesencephalon homeobox 1 (DMBX1), nuclear receptor coactivator 2 (NCOA2), one cut homeobox 2 (ONECUT2) and zing finger protein 83 (ZNF83)] (Table I).

The most significantly enriched BP GO-terms of upregulated DEGs were chromatin assembly or disassembly 


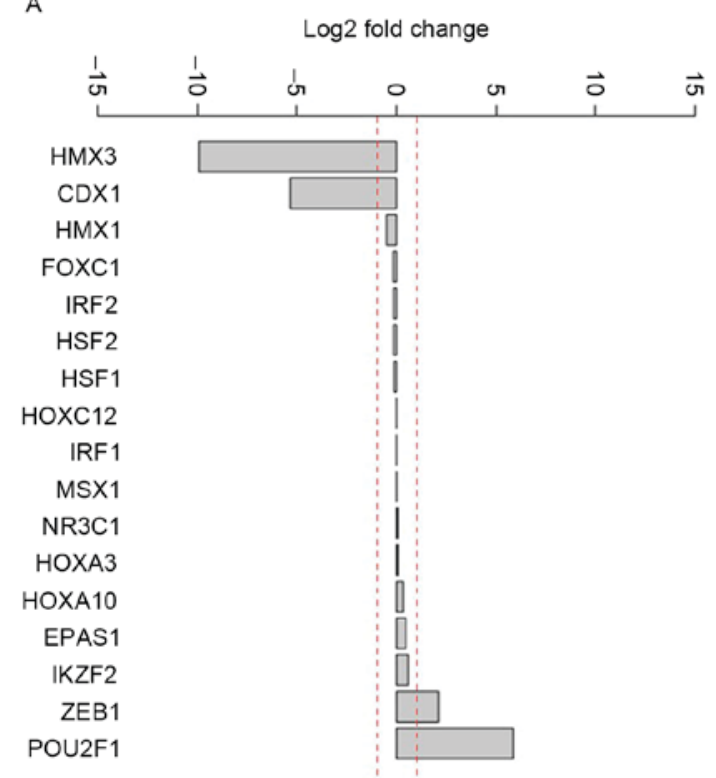

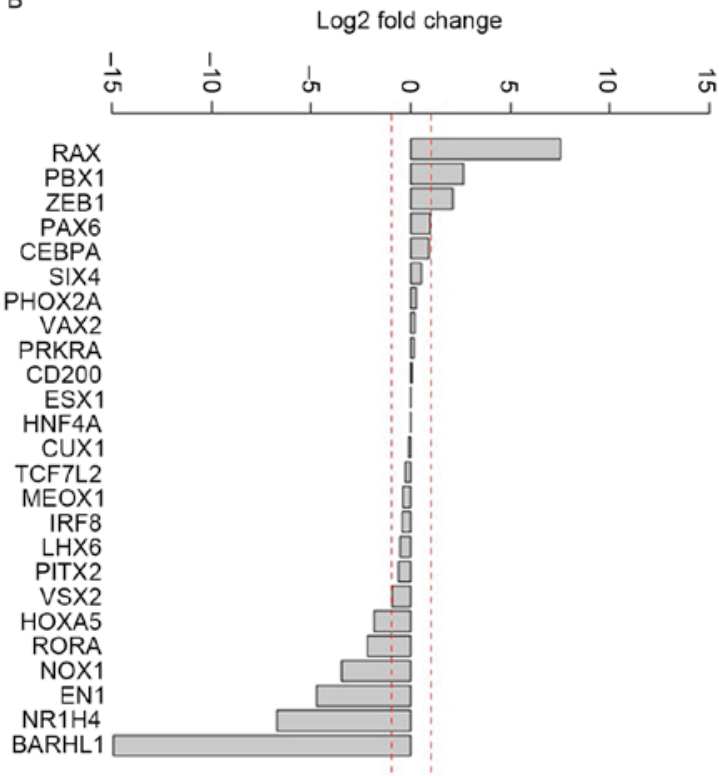

Figure 1. Differential expression of the potential upstream regulatory elements of DEGs in prostate cancer. (A) The expression of the upstream regulatory elements of downregulated DEGs. (B) The expression of the upstream regulatory elements of upregulated DEGs. The red dashed $\operatorname{line}$ represents $\log _{2}$ fold change of 1 or -1 . DEG, differentially-expressed gene.

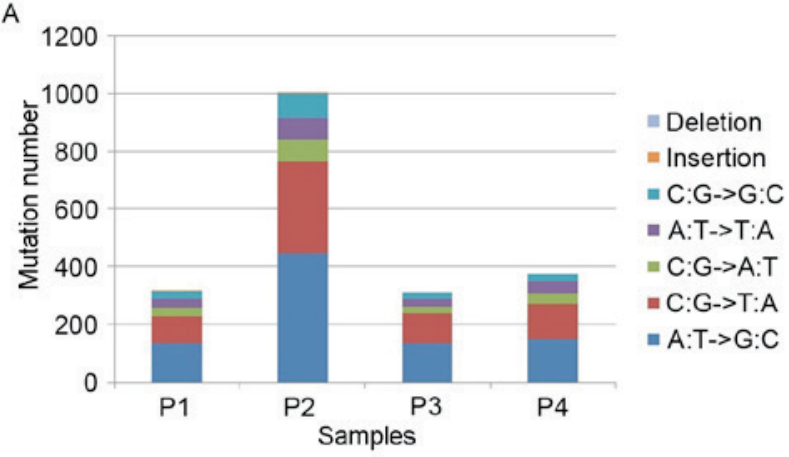

B

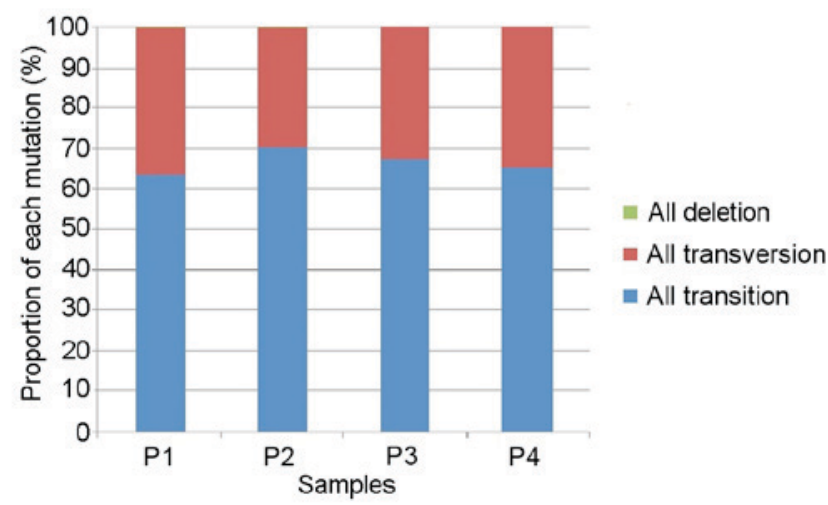

Figure 2. Statistical analysis of somatic mutations in 4 prostate cancer samples. (A) The number of each mutation type in 4 prostate cancer samples. (B) The proportion of each mutation type in 4 cancer samples. P1, P2, P3 and $\mathrm{P} 4$ represent the 4 prostate cancer samples.

$(\mathrm{P}=0.0016)$ and nucleosome assembly $(\mathrm{P}=0.0024)$ (Table II). In addition, the most significant $\mathrm{CC}$ GO-terms identified were nucleosome $(\mathrm{P}=0.0006)$ and protein-DNA complex $(\mathrm{P}=0.0020)$. The results of the present study suggested that
Table IV. High-frequency mutation sites in prostate cancer.

\begin{tabular}{lcccc}
\hline & & \multicolumn{2}{c}{ Base } & \\
\cline { 3 - 4 } Chr & Position & Reference & Mutated & Frequency, n \\
\hline \multirow{2}{*}{ Chr11 } & 89431695 & $\mathrm{~T}$ & $\mathrm{~A}$ & 3 \\
ChrY & 22941450 & $\mathrm{~A}$ & $\mathrm{C}$ & 2 \\
ChrY & 22921933 & $\mathrm{~A}$ & $\mathrm{G}$ & 2 \\
ChrX & 51807602 & $\mathrm{G}$ & $\mathrm{A}$ & 2 \\
ChrX & 43634502 & $\mathrm{~T}$ & $\mathrm{C}$ & 2 \\
Chr9 & 96214432 & $\mathrm{G}$ & $\mathrm{C}$ & 2 \\
Chr7 & 73245681 & $\mathrm{~A}$ & $\mathrm{G}$ & 2 \\
Chr6 & 29692069 & $\mathrm{C}$ & $\mathrm{A}$ & 2 \\
Chr6 & 10749928 & $\mathrm{~A}$ & $\mathrm{G}$ & 2 \\
Chr19 & 51325077 & $\mathrm{G}$ & $\mathrm{T}$ & 2 \\
Chr18 & 3253963 & $\mathrm{C}$ & $\mathrm{G}$ & 2 \\
Chr18 & 21057145 & $\mathrm{C}$ & $\mathrm{G}$ & 2 \\
Chr17 & 60631088 & $\mathrm{~A}$ & $\mathrm{G}$ & 2 \\
Chr16 & 2149965 & $\mathrm{G}$ & $\mathrm{A}$ & 2 \\
Chr15 & 28421681 & $\mathrm{~A}$ & $\mathrm{G}$ & 2 \\
Chr1 & 89474720 & $\mathrm{~T}$ & $\mathrm{C}$ & 2 \\
Chr1 & 147580839 & $\mathrm{~A}$ & $\mathrm{G}$ & 2 \\
\hline & & & & \\
\hline
\end{tabular}

Chr, chromosome.

genes associated with chromatin structure stability may be highly expressed in prostate cancer.

Of the downregulated DEGs, BP GO terms were significantly enriched in glycoprotein metabolic process $(\mathrm{P}=0.0082)$, glycoprotein biosynthetic process $(\mathrm{P}=0.0120)$ and immune response $(\mathrm{P}=0.0162)$; whereas, $\mathrm{CC}$ GO terms were 
Table V. Frequency of high-risk genes in prostate cancer.

\begin{tabular}{|c|c|c|c|c|}
\hline High-risk mutated gene & Gene name & Frequency & $\begin{array}{l}\text { Expression } \\
\text { level }\end{array}$ & $\begin{array}{l}\text { Tumor-associated } \\
\text { gene }\end{array}$ \\
\hline$P P P 4 R 2$ & $\begin{array}{l}\text { Protein phosphatase } 4, \\
\text { regulatory subunit } 2\end{array}$ & 2 & - & - \\
\hline CLDN4 & Claudin 4 & 2 & Upregulated $^{\mathrm{a}}$ & Tumor-associated $^{\mathrm{a}}$ \\
\hline FOLHIB & Folate hydrolase 1B & 3 & Downregulated $^{\mathrm{a}}$ & Tumor-associated $^{\mathrm{a}}$ \\
\hline$K I F 27$ & Kinesin family member 27 & 2 & - & - \\
\hline$M A O B$ & Monoamine oxidase B & 2 & Upregulated $^{\mathrm{a}}$ & Tumor-associated $^{\mathrm{a}}$ \\
\hline$D U X A$ & Double homeobox A & 2 & - & - \\
\hline$K L K 1$ & Kallikrein 1 & 2 & Upregulated & $\begin{array}{l}\text { Tumor suppressor } \\
\text { gene }\end{array}$ \\
\hline MYL12A & $\begin{array}{l}\text { Myosin, light chain } 12 \mathrm{~A} \text {, } \\
\text { regulatory, non-sarcomeric }\end{array}$ & 2 & - & - \\
\hline HERC2 & Hect domain and RLD 2 & 2 & - & - \\
\hline$H L A-E$ & $\begin{array}{l}\text { Major histocompatibility } \\
\text { complex, class I, E }\end{array}$ & 2 & Downregulated $^{\mathrm{a}}$ & $\begin{array}{l}\text { Tumor suppressor } \\
\text { gene }^{\mathrm{a}}\end{array}$ \\
\hline$H L A-G$ & $\begin{array}{l}\text { Major histocompatibility } \\
\text { complex, class I, G }\end{array}$ & 2 & Downregulated $^{\mathrm{a}}$ & Tumor-associated $^{\mathrm{a}}$ \\
\hline RIOK3 & RIO kinase 3 & 2 & - & - \\
\hline RPS4Y2 & $\begin{array}{l}\text { Ribosomal protein } \mathrm{S} 4 \text {, } \\
\text { Y-linked } 2\end{array}$ & 3 & - & - \\
\hline$P K D 1$ & $\begin{array}{l}\text { Polycystic kidney disease } 1 \\
\text { (autosomal dominant) }\end{array}$ & 3 & Upregulated $^{\mathrm{a}}$ & $\begin{array}{l}\text { Tumor suppressor } \\
\text { gene }\end{array}$ \\
\hline USP10 & $\begin{array}{l}\text { Ubiquitin specific } \\
\text { peptidase } 10\end{array}$ & 2 & - & - \\
\hline$T L K 2$ & Tousled-like kinase 2 & 2 & - & - \\
\hline TMEM14B & $\begin{array}{l}\text { Transmembrane protein 14D; } \\
\text { transmembrane protein } 14 \mathrm{~B}\end{array}$ & 2 & - & - \\
\hline TUBAIA & Tubulin, $\alpha$ 1a & 2 & - & - \\
\hline$G B P 3$ & Guanylate binding protein 3 & 2 & - & - \\
\hline$M A G E D 4 B$ & $\begin{array}{l}\text { Melanoma antigen family } D \text {, } \\
\text { 4B; melanoma antigen } \\
\text { family } D, 4\end{array}$ & 2 & - & $\begin{array}{l}\text { Tumor-associated } \\
\text { gene }\end{array}$ \\
\hline
\end{tabular}

aData provided by the OncoSearch database (http://oncosearch.biopathway.org/\#/search).

significantly enriched in the microvillus $(\mathrm{P}=0.0033)$, intrinsic to plasma membrane $(\mathrm{P}=0.0055)$ and plasma membrane part $(\mathrm{P}=0.0129)$ (Table II).

Identification of the upstream regulatory elements of DEGs. Motif scanning of the upstream regulatory elements of up-regulated DEGs revealed 25 transcription factors that may regulate these DEGs (Table III). Additionally, 17 transcription factors were identified to regulate downregulated DEGs (Table III).

Differential expression analysis of the potential upstream regulatory elements demonstrated that the expression of H6 family homeobox 3 and caudal type homeobox 1 were markedly decreased (Fig. 1A). In addition, the following genes were activated in different degrees: Retina and anterior neural fold homeobox, PBX homeobox 1, zinc finger E-box binding homeobox 1, paired box 6 and CCAAT/enhancer binding protein- $\alpha$ (Fig. 1B).
Detection of SNVs in prostate cancer. Following the removal of polymerase chain reaction duplicates and data processing of RNA-seq in 4 prostate cancer samples, 317, 1,004, 310 and 373 somatic mutation sites were identified in 4 prostate cancer samples particularly (Fig. 2). In each sample, base transversion $(\mathrm{C}: \mathrm{G} \rightarrow \mathrm{A}: \mathrm{T} ; \mathrm{A}: \mathrm{T} \rightarrow \mathrm{T}: \mathrm{A} ; \mathrm{C}: \mathrm{G} \rightarrow \mathrm{G}: \mathrm{C})$ and base transition $(\mathrm{A}: \mathrm{T} \rightarrow$ $\mathrm{G}: \mathrm{C} ; \mathrm{C}: \mathrm{G} \rightarrow \mathrm{T}: \mathrm{A})$ were the most common types of base mutation (Fig. 2A). Only one insertion site was identified in the 4 prostate cancer samples. The proportions of each mutation type in the 4 prostate cancer samples were similar, suggesting that $65 \%$ of mutations were base transition and $35 \%$ were base transversion (Fig. 2B).

Mutation sites that occurred in $>2$ prostate cancer samples were defined as a high-frequency site (frequency $\geq 2$ ). A total of 17 mutation sites were identified as high-frequency sites (Table IV). The $\mathrm{T} \rightarrow$ A base transversion of chromosome 1189431695 was identified in 3 cancer samples and its loci was located in the folate hydrolase $1 \mathrm{~B}($ FOLH1B) gene. An 
additional 16 mutation sites were detected in 2 cancer samples and loci were all located in the coding sequence (CDS) region of genes.

The frequency of high-risk mutant genes was calculated using VarioWatch (Table V). A total of 20 high-risk mutant genes were identified, of which ribosomal protein $\mathrm{S} 4 \mathrm{Y}$-linked 2 (RPS4Y2), polycystin 1 transient receptor potential channel interacting $(P K D 1)$ and $F O L H 1 B$ were identified in 3 cancer samples. Furthermore, kallikrein $1(K L K 1)$ and $P K D 1$ were known tumor suppressor genes $(30,31)$. Although the expression level of the $K L K 1$ gene was increased in prostate cancer, the high frequency of mutation located in the CDS region may lead to dysfunction of the tumor suppressor. However, the expression levels of other 19 high-risk genes were not markedly different in prostate cancer, indicating that the abnormal function of these genes, induced by base mutation, may be associated with the development of prostate cancer.

\section{Discussion}

The present study provided a survey of DEGs and mutant genes in human prostate cancer. RNA-seq data between 4 prostate cancer samples and 4 matched normal samples were analyzed. A total 150 upregulated and 211 downregulated DEGs were identified, 4 of which were upregulated transcription factors (DMBX1, NCOA2, ONECUT2 and ZNF83), and 4 were downregulated transcription factors (IFI16, NEUROG3, RARG and SIM1).

NCOA2 has been suggested as an oncogene in primary tumors by increasing androgen receptor signaling, which is known to have a function in early and late-stage prostate cancer (13). Furthermore, the upregulated expression of transcription factor ONECUT2 was revealed in breast and prostate cancer cell lines (32), and increased IFI16 protein in normal human prostate epithelial cells was associated with cellular senescence-associated cell growth arrest (33). NEUROG3 was identified to be expressed in metastatic neuroendocrine prostate cancer cells (34). However, mechanism of abnormal regulation of $D M B X 1, Z N F 83, R A R G$ and SIM1 in prostate cancer remains unknown. For example, the abnormal regulation of ZNF83 has been identified in hepatocellular carcinoma (35) and colorectal cancer (36), but not in prostate cancer. DMBX1 is a paired-class homeodomain transcription factor and may be determined in the brain, stomach and testis in adult normal tissues (37). A previous study focused on the expression pattern of DMBX1 in the development of the neural network (38). Therefore, these aforementioned transcription factors may have important functions in the progress of prostate cancer.

Determining the SNVs in prostate cancer identified 17 mutation sites with a frequency $\geq 2$. The mutation site with the highest frequency was located in FOLH1B. Furthermore, 20 high-risk mutant genes with highest frequency were identified using VarioWatch and included RPS4Y2, PKDI and $F O L H 1 B$. FOLHIB originates from the duplication of folate hydrolase 1 (FOLH1) (39), which is an established biomarker for prostate cancer (40). FOLH1, also known as prostate-specific membrane antigen 1 , is used as a diagnostic and prognostic indicator for prostate cancer, and is associated with aggressiveness and metastasis of prostate cancer (41). Of the identified high-risk mutant genes exhibiting the highest frequency, $K L K 1$ and $P K D 1$ are known tumor suppressor genes and MAGE family member D4B is a tumor-associated gene $(30,31)$. PKD1 has been identified to be downregulated in advanced-stage prostate cancer and was present as a protein complex, combined with the androgen receptor, in prostate cancer cells (42). The kallikrein-related peptidases have been identified in a number of types of cancer, including prostate and ovarian, and a combination of the dysregulation of $K L K 1$, 5 and 13 was associated with poorer disease-free survival for prostate cancer (43). The high frequency of mutation located in $K L K 1, P K D 1$ and $D 4 B$ may lead to dysfunction of the tumor suppressor functions and consequently contribute to the progress of prostate cancer.

There were a number of limitations in the present study; for example, the sample size used for the analysis was small. Furthermore, the results of the present study require validation using other RNA-seq data or microarray data of prostate cancer.

Combined with bioinformatics methods, the RNA-seq data were analyzed to determine candidate genes for diagnosing and/or treating of prostate cancer. The identified DEGs (DMBX1, ZNF83, RARG and SIM1) and mutant genes (RPS4Y2, KLK1 and FOLH1B) may have important functions in the progression of prostate cancer. The results of the present study may enable an improved understanding of the molecular mechanisms that underlie prostate cancer pathogenesis.

\section{References}

1. Siegel R, Ward E, Brawley O and Jemal A: Cancer statistics, 2011: The impact of eliminating socioeconomic and racial disparities on premature cancer deaths. CA Cancer J Clin 61: 212-236, 2011.

2. Jemal A, Bray F, Center MM, Ferlay J, Ward E and Forman D: Global cancer statistics. CA Cancer J Clin 61: 69-90, 2011.

3. Hsing AW and Chokkalingam AP: Prostate cancer epidemiology. Front Biosci 11: 1388-1413, 2006.

4. Miller DC, Hafez KS, Stewart A, Montie JE and Wei JT: Prostate carcinoma presentation, diagnosis and staging: An update form the National Cancer Data Base. Cancer 98: 1169-1178, 2003.

5. Leitzmann MF and Rohrmann S: Risk factors for the onset of prostatic cancer: Age, location, and behavioral correlates. Clin Epidemiol 4: 1-11, 2012.

6. Schaid DJ: The complex genetic epidemiology of prostate cancer. Hum Mol Genet 13 Spec No 1: R103-R121, 2004.

7. Mahmoud AM, Yang W and Bosland MC: Soy isoflavones and prostate cancer: A review of molecular mechanism. J Steroid Biochem Mol Biol 140: 116-132, 2014.

8. Watson PA, Arora VK and Sawyers CL: Emerging mechanisms of resistance to androgen receptor inhibitors in prostate cancer. Nat Rev Cancer 15: 701-711, 2015.

9. Pflueger D, Terry S, Sboner A, Habegger L, Esgueva R, Lin PC, Svensson MA, Kitabayashi N, Moss BJ, MacDonald TY, et al: Discovery of non-ETS gene fusions in human prostate cancer using next-generation RNA sequencing. Genome Res 21: 56-67, 2011.

10. Narla G, Heath KE, Reeves HL, Li D, Giono LE, Kimmelman AC, Glucksman MJ, Narla J, Eng FJ, Chan AM, et al: KLF6, a candidate tumor suppressor gene mutated in prostate cancer. Science 294: 2563-2566, 2001.

11. Majid S, Dar AA, Shahryari V, Hirata H, Ahmad A, Saini S, Tanaka Y, Dahiya AV and Dahiya R: Genistein reverses hypermethylation and induces active histone modifications in tumor suppressor gene B-Cell translocation gene 3 in prostate cancer. Cancer 116: 66-76, 2010.

12. Carver BS, Tran J, Gopalan A, Chen Z, Shaikh S, Carracedo A, Alimonti A, Nardella C, Varmeh S, Scardino PT, et al: Aberrant ERG expression cooperates with loss of PTEN to promote cancer progression in the prostate. Nat Genet 41: 619-624, 2009. 
13. Taylor BS, Schultz N, Hieronymus H, Gopalan A, Xiao Y, Carver BS, Arora VK, Kaushik P, Cerami E, Reva B, et al: Integrative genomic profiling of human prostate cancer. Cancer cell 18: 11-22, 2010

14. Wang Z, Gerstein M and Snyder M: RNA-Seq: A revolutionary tool for transcriptomics. Nat Rev Genet 10: 57-63, 2009.

15. Ren S, Peng Z, Mao JH, Yu Y, Yin C, Gao X, Cui Z, Zhang J, Yi K, $\mathrm{Xu} \mathrm{W}$, et al: RNA-seq analysis of prostate cancer in the Chinese population identifies recurrent gene fusions, cancer-associated long noncoding RNAs and aberrant alternative splicings. Cell Res 22: 806-821, 2012.

16. Kannan K, Wang L, Wang J, Ittmann MM, Li W and Yen L: Recurrent chimeric RNAs enriched in human prostate cancer identified by deep sequencing. Proc Natl Acad Sci USA 108: 9172-9177, 2011.

17. Xu X, Zhu K, Liu F, Wang Y, Shen J, Jin J, Wang Z, Chen L, Li J and Xu M: Identification of somatic mutations in human prostate cancer by RNA-Seq. Gene 519: 343-347, 2013.

18. Makarov DV, Trock BJ, Humphreys EB, Mangold LA, Walsh PC, Epstein JI and Partin AW: Updated nomogram to predict pathological stage of prostate cance given prostate-specific antigen level, clinical stage, and biopsy Gleason score (Partin tables) based on cases from 2000 to 2005. Urology 69: 1095-1101, 2007.

19. Trapnell C, Pachter L and Salzberg SL: TopHat: Discovering splice junctions with RNA-Seq. Bioinformatics 25: 1105-1111, 2009.

20. Pruitt KD, Tatusova T and Maglott DR: NCBI reference sequences (RefSeq): A curated non-redundant sequence database of genomes, transcripts and proteins. Nucleic Acids Res 35 (Database Issue): D61-D65, 2007.

21. Trapnell C, Roberts A, Goff L, Pertea G, Kim D, Kelley DR, Pimentel H, Salzberg SL, Rinn JL and Pachter L: Differential gene and transcript expression analysis of RNA-seq experiments with TopHat and Cufflinks. Nat Protoc 7: 562-578, 2012.

22. Beane J, Vick J, Schembri F, Anderlind C, Gower A, Campbell J, Luo L, Zhang XH, Xiao J, Alekseyev YO, et al: Characterizing the impact of smoking and lung cancer on the airway transcriptome using RNA-Seq. Cancer Prev Res (Phila) 4: 803-817, 2011.

23. Hulsegge I, Kommadath A and Smits MA: Globaltest and GOEAST: Two different approaches for Gene Ontology analysis. BMC Proc 3 (Suppl 4): S10, 2009.

24. Huang da W, Sherman BT and Lempicki R: Systematic and integrative analysis of large gene lists using DAVID bioinformatics resources. Nat Protoc 4: 44-57, 2009.

25. Zhao M, Sun J and Zhao Z: TSGene: A web resource for tumor suppressor genes. Nucleic Acids Res 41 (Database Issue) D970-D976, 2013

26. Chen JS, Hung WS, Chan HH, Tsai SJ and Sun HS: In silico identification of oncogenic potential of fyn-related kinase in hepatocellular carcinoma. Bioinformatics 29: 420-427, 2013.

27. He HH, Meyer CA, Shin H, Bailey ST, Wei G, Wang Q, Zhang Y, $\mathrm{Xu} \mathrm{K}, \mathrm{Ni} \mathrm{M}$, Lupien M, et al: Nucleosome dynamics define transcriptional enhancers. Nat Genet 42: 343-347, 2010.

28. McKenna A, Hanna M, Banks E, Sivachenko A, Cibulskis K, Kernytsky A, Garimella K, Altshuler D, Gabriel S, Daly M and DePristo MA: The genome analysis toolkit: A MapReduce framework for analyzing next-generation DNA sequencing data. Genome Res 20: 1297-1303, 2010.
29. Cheng YC, Hsiao FC, Yeh EC, Lin WJ, Tang CY, Tseng HC, Wu HT, Liu CK, Chen CC, Chen YT and Yao A: VarioWatch: Providing large-scale and comprehensive annotations on human genomic variants in the next generation sequencing era. Nucleic Acids Res 40 (Web Server Issue): W76-W81, 2012.

30. Raea F, Bulmera B, Nicolb D and Clementsa J: The human tissue kallikreins (KLKs 1-3) and a novel KLK1 mRNA transcript are expressed in a renal cell carcinoma cDNA library. Immnuopharmacology 45: 83-88, 1999.

31. Shabelnik MY, Kovalevska LM, Yurchenko MY, Shlapatska LM, Rzepetsky Y and Sidorenko S: Differential expression of PKD1 and PKD2 in gastric cancer and analysis of PKD1 and PKD2 function in the model system. Exp Oncol 33: 206-211, 2011.

32. Yamamoto $F$ and Yamamoto M: Scanning copy number and gene expression on the 18q21-qter chromosomal region by the systematic multiplex PCR and reverse transcription-PCR methods. Electrophoresis 28: 1882-1895, 2007.

33. Alimirah F, Chen J, Davis FJ and Choubey D: IFI16 in human prostate cancer. Mol Cancer Res 5: 251-259, 2007.

34. Telesca D, Inoue LY, Neira M, Etzioni R, Gleave M and Nelson C: Differential expression and network inferences through functional data modeling. Biometrics 65: 793-804, 2009.

35. Dong H, Ge X, Shen Y, Chen L, Kong Y, Zhang H, Man X, Tang L, Yuan H, Wang H, et al: Gene expression profile analysis of human hepatocellular carcinoma using SAGE and LongSAGE. BMC Med Genomics 2: 5, 2009.

36. Jovov B, Araujo-Perez F, Sigel CS, Stratford JK, McCoy AN, Yeh JJ and Keku T: Differential gene expression between African American and European American colorectal cancer patients. PLoS One 7: e30168, 2012.

37. Ohtoshi A, Nishijima I, Justice MJ and Behringer RR: Dmbx1, A novel evolutionarily conserved paired-like homeobox gene expressed in the brain of mouse embryos. Mech Dev 110: 241-244, 2002

38. Fujimoto W, Shiuchi T, Miki T, Minokoshi Y, Takahashi Y, Takeuchi A, Kimura K, Saito M, Iwanaga T and Seino S: Dmbx 1 is essential in agouti-related protein action. Proc Natl Acad Sci USA 104: 15514-15519, 2007.

39. De Lorenzi L, Genualdo V, Gimelli S, Rossi E, Perucatti A, Iannuzzi A, Zannotti M, Malagutti L, Molteni L, Iannuzzi L and Parma P: Genomic analysis of cattle rob $(1 ; 29)$. Chromosome Res 20: 815-823, 2012

40. Zhang T, Song B, Zhu W, Xu X, Gong QQ, Morando C, Dassopoulos T, Newberry RD, Hunt SR and Li E: An Ileal Crohn's disease gene signature based on whole human genome expression profiles of disease unaffected ileal mucosal biopsies. PLoS One 7: e37139, 2012.

41. Ergün A, Lawrence CA, Kohanski MA, Brennan TA and Collins JJ: A network biology approach to prostate cancer. Mol Syst Biol 3: 82, 2007.

42. Mak P, Jaggi M, Syed V, Chauhan SC, Hassan S, Biswas H and Balaji KC: Protein kinase D1 (PKD1) influences androgen receptor (AR) function in prostate cancer cells. Biochem Biophys Res Commun 373: 618-623, 2008.

43. Girgis AH, Bui A, White NM and Yousef GM: Integrated genomic characterization of the kallikrein gene locus in cancer. Anticancer Res 32: 957-963, 2012. 